\title{
Modern Trends in Inorganic Chemistry (MTIC-XIV)
}

\section{Foreword}

This Special Issue is based on the contributions from the invited speakers of the Fourteenth Symposium on Modern Trends in Inorganic Chemistry (MTIC-XIV) held at the University of Hyderabad during 10-13, December 2011. The MTIC series of biennial symposia have been an important forum for the inorganic chemists of the country to focus on the current status as well as the future developments in the frontier areas of research in this discipline. The topics covered in this issue span a diverse range from bioinorganic chemistry to materials chemistry, encompassing the traditional areas of coordination chemistry, main group chemistry and organometallic chemistry.

The organizers of MTIC-XIV thank the Indian Academy of Sciences, Bangalore for agreeing to bring out this special issue and the Editor, Journal of Chemical Sciences for his support and encouragement. The organizers are grateful to all the authors for their timely contributions and reviewers for their valuable help. Our sincere thanks are also due to the editorial staff of the Journal for their sustained efforts in bringing out this special issue.

2 November 2012

K C KUMARA SWAMY

School of Chemistry, University of Hyderabad, Hyderabad 500 046, India e-mail: kckssc@uohyd.ernet.in

(Guest Editor) 